\title{
A review on the recent history of wind power ramp forecasting
}

\author{
Cristobal Gallego-Castillo , Alvaro Cuerva-Tejero, Oscar Lopez-Garcia \\ DAVE-ETSIAE, Universidad Politécnica de Madrid. Pza Cardenal Cisneros, 3, 28040 Madrid, Spain
}

\begin{abstract}
A B S T R A C T
Forecasting large and fast variations of wind power (the so-called ramps) helps achieve the integration of large amounts of wind energy. This paper presents a survey on wind power ramp forecasting, reflecting the increasing interest on this topic observed since 2007. Three main aspects were identified from the literature: wind power ramp definition, ramp underlying meteorological causes and experiences in predicting ramps. In this framework, we additionally outline a number of recommendations and potential lines of research.
\end{abstract}

\section{Introduction}

Wind energy shows clear advantages as compared with traditional energy sources. However, one of the main drawbacks of wind energy is that it exhibits intermittent generation greatly depending on environmental conditions. Intermittency adds complexity to the management of power systems because supply and demand must be balanced almost instantaneously. Potential solutions are demand response techniques (such as plug-in vehicles) and large scale storage (such as supercapacitors and hydrogen storage) [1], though these might be available only in the middle/long-term. Instead, wind power intermittency can be partly mitigated through forecasting techniques, which aim at reducing the uncertainty of future wind generation of a wind farm or portfolio. In a few decades, approaches to wind power forecasting have evolved rapidly, with special emphasis in the short- term (prediction horizons up to one day). For a detailed review on the topic, readers are referred to Costa et al. [2], Giebel [3], and Jung and Broadwater [4].

In the last few years, the so-called ramp events have attracted growing interest in the wind power forecasting community. The idea behind the notion of a ramp is that a local event (in the form of a large and fast power variation in a wind farm or portfolio) is critical enough to deserve special attention. By critical we mean that the potential damage or cost associated to a bad management of the event is considered too high or, at least, qualitatively higher than that associated to non-ramp situations. An example would be a scenario of load curtailments due to a severe drop of wind power generation. Real experiences of critical events from the grid operator standpoint have been documented by Ela and Kirby [5] and Wan [6]. Energy traders operating in electricity markets might also be affected by ramps, as inaccurate bids during these events may derive in expensive penalties [7]. Despite these situations, according to Potter et al. [8], the impact of ramp events may be occasionally undervalued by forecasters because wind power forecasting traditionally focuses on minimising 
the overall error committed in long time periods (i.e. months, years). This would justify ramp forecasting as a particular case of wind power forecasting specifically oriented to improve the forecast of such events.

The booming importance of wind power ramp forecasting is observed in the increasing number of studies and projects on this topic, as illustrated in Fig. 1. This figure shows the number of wind power ramp-related works on a yearly basis since 2007 (for a detailed list of references, see Table 1). Data for each year are broken down according to type of work (technical report, conference paper; doctoral thesis, non-JCR paper and JCR paper). It is noted that records concerning 2014 are computed only up to August, meaning that the final number of works published in this year is likely to fit with the general positive trend observed in the picture. Another interesting remark is that publications in the form of technical reports predominate in a first stage (2007-2008), while conference papers

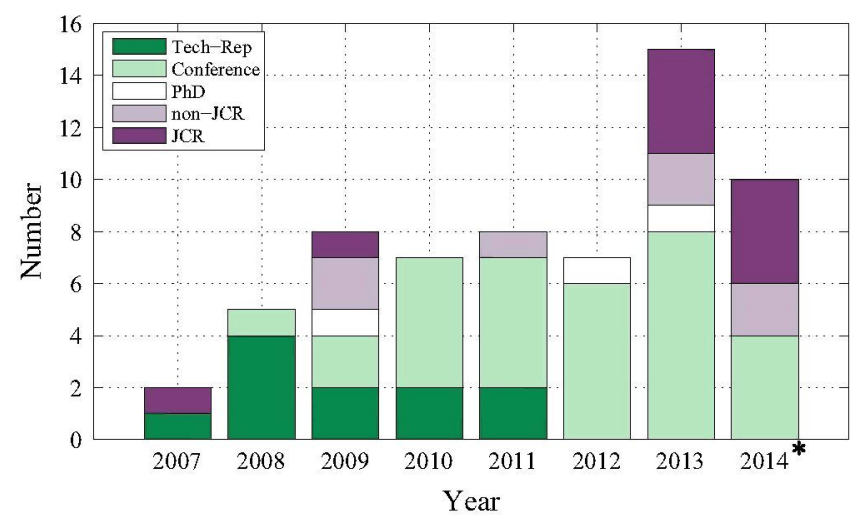

Fig. 1. Number of wind power ramp-related works depicted on a yearly basis and broken down according to type of work. * denotes data up to August 2014.

Table 1

References of the works considered in Fig. 1.

\begin{tabular}{llllll}
\hline Year & Technical report & Conference & Ph.D. & non-JCR & JCR \\
\hline 2007 & {$[9]$} & - & - & - & {$[10]$} \\
2008 & {$[5,11-13]$} & {$[14]$} & - & - & - \\
2009 & {$[15,16]$} & {$[8,17]$} & {$[18]$} & {$[7,19]$} & {$[20]$} \\
2010 & {$[21,22]$} & {$[23-27]$} & - & - & - \\
2011 & {$[6,28]$} & {$[29-33]$} & - & {$[34]$} & - \\
2012 & - & {$[35-40]$} & {$[41]$} & - & - \\
2013 & & {$[42-49]$} & {$[50]$} & {$[51,52]$} & {$[53-56]$} \\
$2014^{*}$ & - & {$[57-60]$} & - & {$[61,62]$} & {$[63-66]$} \\
\hline
\end{tabular}

*Denotes data up to August 2014. become more frequent since 2010 , followed by a noticeable increase of JCR articles experienced in recent years.

The geographical distribution of the case studies considered in wind power ramp-related works is shown in Fig. 2. As expected, ramp events have become a concern in regions with significant levels of wind power penetration. In particular, North America accumulates most of the case studies addressed in the reviewed works: 13 case studies in the Electric Reliability Council of Texas (ERCOT), 9 in the area managed by the Bonneville Power Administration (BPA) and 6 in the Alberta region. Other regions with prominent research activity on wind power ramps are Europe (16 case studies, half of them located in the Iberian peninsula) and Australia (in particular, South Australia and Tasmania). More recently, a few publications considered case studies in growing economies (China and India), where wind power is being developed rapidly.

This paper is devoted to provide an overview on wind power ramp forecasting, along with a brief summary of current open questions and future lines of research. It is noted that a review on this topic was already published in 2010 [22]. Nevertheless, research on ramp events has experienced a noticeable increase since then, as shown in the figures above. For this reason, this paper also aims to update the aforementioned work.

The paper is organised as follows. The following three sections deal with the main aspects on wind power ramps identified from the literature: Section 2 addresses the notion of ramp event; in Section 3 relevant findings on ramp underlying meteorological causes are reviewed; Section 4 gathers approaches and experiences oriented to wind power ramp forecasting. The paper ends with Section 5 highlighting some of the weak points identified from the literature, and suggesting potential lines of research on the topic.

\section{Ramp definition}

Generally speaking, a ramp event represents a large and fast variation in power in a wind farm or portfolio. According to the literature ([22] and references therein), a ramp can be characterised by the following parameters:

- Magnitude $\left(\Delta P_{r}\right)$ : the variation in power observed during the event

- Duration $\left(\Delta t_{r}\right)$ : the time period in which a large variation takes place.

- Ramp rate, which is derived from the previous variables $\left(\Delta P_{r} / \Delta t_{r}\right)$ and provides an idea of the ramp intensity.

- Timing $\left(t_{0}\right)$ : a time instant related to the ramp occurrence. This parameter can be defined either as the starting time or the central time of the event.

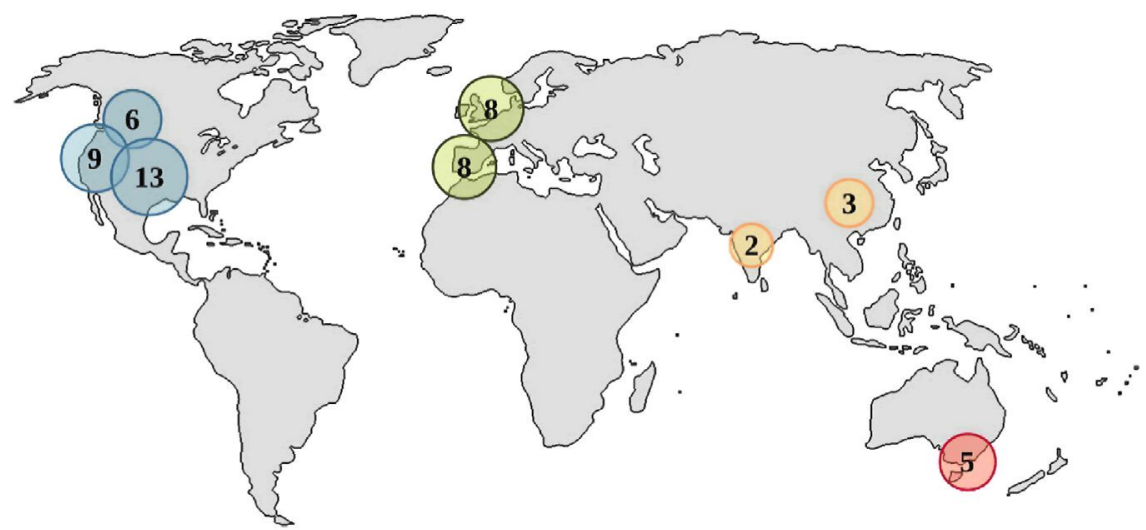

Fig. 2. Regional distribution of the case studies considered in wind power ramp-related works (see text for details). 
- Direction: whether the ramp event represents an increase or a decrease in power.

Some of these parameters are reflected in Fig. 3 for the case of two consecutive ramp events observed in a wind farm located in Spain.

Provided a ramp event within a wind power time series, the aforementioned parameters can be easily assessed. In this line, some works analyse the ramping behaviour of wind power generation data by performing statistics on the magnitude and duration of power gradients $[6,15,49]$. However, ramp forecasting

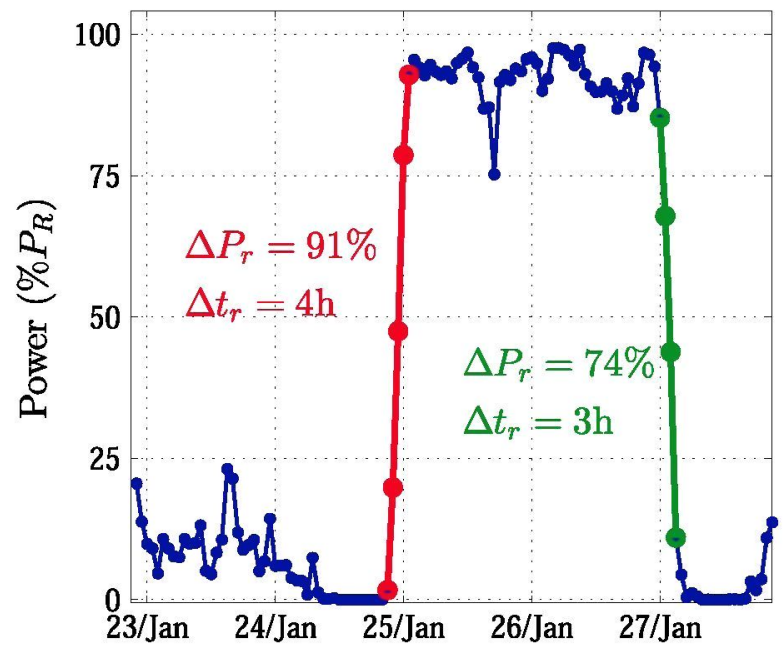

Fig. 3. Two examples of ramp events experienced in a wind farm located in Spain. Some of the parameters usually employed to characterise ramps are indicated the direction is given by the colour: red colour for ramp-up and green colour for rampdown). (For interpretation of the references to colour in this figure caption, the reader is referred to the web version of this paper.) usually entails the inverse problem, that is, provided some criteria, forecasters need to identify ramp events in order to analyse the underlying causes and perform appropriate models. This translates into a need for setting such criteria, i.e. a ramp definition.

In order to identify ramps within wind power time series, most of the works consider a ramp binary classification (a comprehensive list of references is given below in Table 2). The binary classification is based on the indicator function, $I_{t}$, defined as follows:

$I_{t}= \begin{cases}1 & \text { if } S_{t} \geq S_{0} \\ 0 & \text { if } S_{t}<S_{0}\end{cases}$

with $S_{t}$ being a certain criterion function, $S_{t}: \mathbb{R}^{n} \longrightarrow \mathbb{R}$, evaluated at time $t$ and $S_{0} \in \mathbb{R}$ represents a threshold value. Hence, a specific event occurs during a period of time that makes the criterion function to go above a given threshold (i.e., $I_{t}=1$ ). The indicator function allows for the identification of ramp events in a wind power time series merely by considering a certain criterion function together with a threshold. This criterion is usually based on the variation observed between two records of the power time series. Mathematically,

$S_{t}=P_{t+\Delta t_{r}}-P_{t}$.

In this case, the sign of the variation permits one to determine whether a ramp is positive, $S_{t}>\Delta P_{0}$ (thus $I_{t}=1$ for $\left[t, t+\Delta t_{r}\right]$ ) or negative, $S_{t}<-\Delta P_{0}$ (thus $I_{t}=-1$ for $\left[t, t+\Delta t_{r}\right]$ ), $\Delta P_{0}>0$ being the threshold value. Since this definition only takes into account the end values of a specific time interval, consecutive ramps with different direction may lead to an inaccurate ramp identification. To avoid this, an alternative criterion function was proposed by Kamath [26]:

$S_{t}=\max \left(\left[P_{t}, P_{t+\Delta t_{r}}\right]\right)-\min \left(\left[P_{t}, P_{t+\Delta t_{r}}\right]\right)$.

The counterpart of this definition is that the ramp direction is not obtained because the criterion is positive for both ramp-up

Table 2

Binary ramp definitions reviewed in the literature.

\begin{tabular}{|c|c|c|c|c|}
\hline Author & $\Delta P_{0}$ & $\Delta t_{r}$ & Case study size & Comment \\
\hline Cutler $[10]$ & $75 \% P_{R}$ & $3 \mathrm{~h}$ & $65 \mathrm{MW}$ & Hourly resolution \\
\hline Cutler $[10]$ & $65 \% P_{R}$ & $1 \mathrm{~h}$ & $65 \mathrm{MW}$ & 10 -min resolution \\
\hline Freedman [12] & $200 \mathrm{MW}$ & $30 \mathrm{~min}$ & $\sim 1 \mathrm{GW}$ & \\
\hline Truewind [11] & $20 \% P_{R}$ & $1 \mathrm{~h}$ & $\mathrm{n} / \mathrm{s}$ (portfolio) & Threshold for ramp-up \\
\hline Truewind [11] & $15 \% P_{R}$ & $1 \mathrm{~h}$ & $\mathrm{n} / \mathrm{s}$ (portfolio) & Threshold for ramp-down \\
\hline Potter [8] & $10 \% P_{R}$ & $1 \mathrm{~h}$ & $\sim 1 \mathrm{GW}$ & \\
\hline Greaves [7] & $50 \% P_{R}$ & $4 \mathrm{~h}$ & $3-240 \mathrm{MW}$ & \\
\hline Barbour [21] & $20 \% P_{R}$ & $30 \mathrm{~min}$ & $\sim 200 \mathrm{MW}$ & Core ramp \\
\hline Collier $[25]$ & $50 \% P_{R}$ & $4 \mathrm{~h}$ & $\mathrm{n} / \mathrm{s}$ & \\
\hline Bradford [24] & $20 \% P_{R}$ & $1 \mathrm{~h}$ & $\mathrm{n} / \mathrm{s}$ (wind farm) & \\
\hline Bossavy [23] & $50 \% P_{R}$ & $\mathrm{n} / \mathrm{a}$ & $\mathrm{n} / \mathrm{s}$ (wind farm) & \\
\hline Kamath [30] & $10-12 \% P_{R}$ & $30 \mathrm{~min}$ & $\sim 1 \mathrm{GW}$ & \\
\hline Kamath [30] & $15-20 \% P_{R}$ & $1 \mathrm{~h}$ & $\sim 1 \mathrm{GW}$ & \\
\hline Gallego-Castillo [34] & $\sigma_{\mathrm{g}}$ & $1 \mathrm{~h}$ & $33 \mathrm{MW}$ & \\
\hline Cutler [28] & $200 \mathrm{MW}$ & $30 \mathrm{~min}$ & $868 \mathrm{MW}$ & \\
\hline Cutler [28] & $150 \mathrm{MW}$ & $5 \mathrm{~min}$ & $868 \mathrm{MW}$ & Threshold for ramp-down \\
\hline Cutler [28] & $150 \mathrm{MW}$ & $30 \mathrm{~min}$ & $286 \mathrm{MW}$ & \\
\hline Cutler [28] & $75 \mathrm{MW}$ & $30 \mathrm{~min}$ & $140 \mathrm{MW}$ & \\
\hline Zareipour [31] & $50 \mathrm{MW}$ & $10 \mathrm{~min}$ & $\mathrm{n} / \mathrm{s}$ (portfolio) & \\
\hline Pinson [35] & $50 \% P_{R}$ & $4 \mathrm{~h}$ & $\mathrm{n} / \mathrm{s}$ (wind farm) & \\
\hline Bossavy [54] & $30 \% P_{R}$ & $\mathrm{n} / \mathrm{a}$ & $8 \mathrm{MW}$ & \\
\hline Yang [56] & $15 \% P_{R}$ & $1 \mathrm{~h}$ & $\mathrm{n} / \mathrm{a}$ & \\
\hline Fernandez [42] & $25 \% P_{R}$ & $3 \mathrm{~h}$ & $18 \mathrm{MW}$ & \\
\hline Suzuki [45] & $15 \% P_{R}$ & $6 \mathrm{~h}$ & $\mathrm{n} / \mathrm{s}$ (wind farm) & \\
\hline Revheim [58] & $30 \% P_{R}$ & $3 \mathrm{~h}$ & $\mathrm{n} / \mathrm{a}$ & \\
\hline Heckenbergerova [57] & $50 \% P_{R}$ & $5 \mathrm{~h}$ & $68 \mathrm{MW}$ & \\
\hline Gan [61] & $40 \% P_{R}$ & $\mathrm{n} / \mathrm{a}$ & $\mathrm{n} / \mathrm{s}$ (wind farm) & Threshold for ramp-up \\
\hline Gan [61] & $30 \% P_{R}$ & $\mathrm{n} / \mathrm{a}$ & $\mathrm{n} / \mathrm{s}$ (wind farm) & Threshold for ramp-down \\
\hline
\end{tabular}

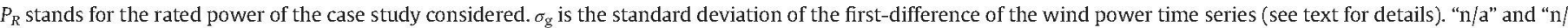
$s$ " stands for "not applicable" and "not specified", respectively. 
and ramp-down events. Likewise, Kamath [26] noted that the use of the criterion given in (2) or the one given in (3) had little effect on the statistics obtained in the study.

The threshold $\Delta P_{0}$ is usually expressed as a percentage of the installed capacity, $\% P_{R}$ (see Table 2 below), though a few works considering large regions have employed an absolute power amplitude threshold $[12,28]$. In Kamath [26], it is argued that the latter option is more appropriate because the installed capacity is likely to vary along time as existing wind turbines are upgraded or new wind farms are installed. In this situation, a threshold based on rated power percentage would identify the same event differently in distant times. In addition, the absolute threshold value may be set in base of technical criteria such as the back-up generation available (reserves provided by conventional generation). Nevertheless, the counterpart of the absolute threshold value is that a higher frequency of ramp events is likely to be observed as the installed capacity increases [30].

Some authors have proposed a different criterion to set the threshold value. Gallego-Castillo et al. [34] proposed $\Delta P_{0}$ to be defined as a percentage of $\sigma_{g}$, the standard deviation of the firstdifference wind power time series. ${ }^{1}$ In Fernández et al. [42], the value for $\Delta P_{0}$ is set so that ramp events occur $5 \%$ of the time.

A few works opted for time-varying threshold, expressed as a percentage of the current generated power during the event $[56,64]$. According to Yang et al. [56], this choice seems to unnecessarily complicate the ramp definition because ramp identification becomes inaccurate for low values of the actual generated power, and additional constraints shall be required.

An attempt to provide a more sophisticated and reliable ramp definition was made during the ramp forecasting project described by Barbour et al. [21], where a ramp was identified based on two features: the core ramp, which represents a large variation in wind power output, and the refinement, comprised the pre/post-time intervals if a substantial power variation (smaller than the core, but larger than a certain threshold) in the same direction was observed. Despite the seemingly clarity of the definition, different interpretations were initially made by the participants, who agreed on a common ramp definition only during the last months of the project.

Computing the indicator function from the wind power time series was deemed unsuitable in Bossavy et al. [23] because wind power may exhibit high variability in time scales shorter than typical ramp lengths. As a consequence, ramp identification may become highly sensitive to fast fluctuations or noise. To avoid this problem, a criterion function based on a filtered signal, $\left\{p_{t}^{f}\right\}$, was proposed. The filtered signal is obtained from a low-pass filter where a parameter related to the number of averaged measures, $n$, must be set. Mathematically,

$S_{t}=p_{t}^{f}=\operatorname{mean}\left\{p_{t+h}-p_{t+h-n} ; h=1, \ldots, n\right\}$

The parameter $n$ permits us to tune the sensitivity to short period variations in the original time series (i.e., the characteristic time length of the ramps which are considered of interest). Setting the value of $n$ replaces the duration parameter $\Delta t_{r}$ employed in previous definitions.

Despite a few exceptions, the most employed criterion for ramp identification is the one provided in Eq. (2). In this case, the key elements in defining a ramp event are the threshold values $\left(\Delta P_{0}, \Delta t_{r}\right)$. Table 2 summarises the thresholds reviewed, clearly showing the extent to which different ramp definitions have been considered in the literature (the amplitude threshold ranges from $10 \% P_{R}$ to $75 \% P_{R}$ and the duration threshold stretches from $5 \mathrm{~min}$ to $6 \mathrm{~h}$ ). It is worth mentioning that most of these thresholds were assessed with little or no discussion on their suitability, reflecting

\footnotetext{
${ }^{1}$ The first-difference of a certain time series $\left\{p_{t}\right\}$ is defined as $\Delta p_{t}=p_{t}-p_{t-1}$.
}

a lack of agreement with end-users of what could be considered a problematic event. In these regard, the most prominent exception is that of Cutler et al. [28], where, according to the Australian Energy Market Operator, several ramp categories leading to significant power system disturbances were employed.

The binary ramp definition was called into question by GallegoCastillo et al. [53]. According to the authors, the number of ramp events identified within a wind power time series may become very sensitive with respect to the threshold values. In addition, a ramp binary classification supports the notion that ramps are similar to one another, in spite of the fact that ramps with different characteristics are usually observed. In order to overcome these drawbacks, the so-called ramp function was introduced in order to characterise the ramp intensity through a continuous-valued index. Some applications of the ramp function were described in [50] and [53]. In this line, a fuzzy approach for wind power ramp characterisation was presented in MartnezArellano et al. [62]. Bossavy et al. [63] proposed a comprehensive framework for evaluating and comparing different continuous-valued approaches for wind power ramp characterisation. Probably, the main limitation of that work is the use of synthetic wind power time series with specific ramp patterns. This constraints the obtained conclusions as real data are likely to show a wider variety of complex situations.

\section{Ramp underlying meteorological processes}

As stated in [11], the understanding of the meteorological phenomena that cause large ramp events is an important precursor to the development of a successful large ramp forecast procedure. This is so because the identification of the meteorological scales relevant in explaining ramp events may provide insights about the accuracy that could be expected with current Numerical Weather Prediction (NWP) models, as well as what efforts could be made to adapt them for ramp forecasting. Nevertheless, relating ramps to their underlying causes is a very case-dependent problem. First, it is rarely the case that different wind farm locations are characterised by similar meteorological conditions. Even when two placements are located at similar latitudes (which may suggest similar macro-scale conditions), local effects may become quite different due to specific terrain characteristics, roughness, topography or sea-land interactions. In addition, the lay-out of the wind farm (i.e. row-configured wind farms versus squared distribution) may place conditions to the occurrence of ramps during meteorological processes involving changes in wind direction. Another issue is the size of the area considered. If the aggregated wind power output of a large area is considered, it is expected that large ramp events would be related to large scale meteorological processes so that most of the wind farms would be affected at the same time. Conversely, micro- and mesoscale processes characterised by short time and spatial scales may become relevant in explaining sudden variations in wind power output of a single wind farm. In some cases, the specific site conditions are also determinant in explaining the scale of the processes involved in ramp events [10]. Cutler et al. [10] probably constitutes the first work in analysing wind power ramps. This work focuses on a single wind farm, located in North-west coast of Tasmania. It was found that the specific site conditions reduced the influence of local effects so that large ramp events were found to be mainly related to large scale processes, such as low pressure systems and fronts. It was also noted that ramp events were evenly distributed over the day and they were less frequent in autumn.

An interesting classification of the main meteorological processes that may derive in ramp events was provided by Zack [9]. According to the author, one can distinguish between phenomena driven by horizontal atmospheric processes and those driven by vertical atmospheric processes. Among the former, processes related to two 
different scales can be described: passage of large-scale weather systems (such as fronts) and the onset of local/mesoscale circulations (such as sea-land breezes and mountain-valley winds). In both cases the state of the art in NWP models permits relatively good forecasts of these processes. On the other hand, phenomena driven by vertical processes (convection) are likely to be much difficult to predict. It is due to the fact that these phenomena are characterised by short life cycles, as well as a high sensitivity to perturbations of certain variables, such as turbulent mixing. For example, the existence of a high wind speed layer above the wind turbine level along with a sudden perturbation in stability conditions can derive in a vertical mixing of momentum, leading to high wind speeds at lower heights and causing an explosive increase in wind power output. Other example would be the sudden onset of a thunderstorm (usually referred to as moist convection). However, the author noted that even if current NWP models hardly forecast these events in timing and location, they can provide useful information related to favourable environmental conditions for the mentioned processes.

In a similar vein, Musilek and $\mathrm{Li}$ [32] differentiated between meteorological processes typically causing ramp-up events (cold front, thunderstorm outflow, onset of mountain wave events and sea breezes) and ramp-down events (relaxation after cold front, boundary stabilisation and warm front). Special attention was placed to cold fronts, as the author sets a framework for detecting such events based on three weather features: temperature drop, wind shift and pressure trough.

A well-documented case study was performed in the ERCOT area, where wind energy deployment plans have led to high wind power penetration levels. Freedman et al. [12] compiled the main meteorological underlying processes of aggregated wind power ramp events observed during the years 2005 and 2006, and a very well detailed analysis on some specific ramp events was performed. From a statistical point of view, ramp-up events were found to be more frequent than ramp-down events. This fact seems to be explained by the passage of weather systems such as fronts that usually provoke sudden wind increases followed by a gradual decline. In addition, it was noted that ramp-up events were primarily caused by convective events during the hot season (mainly observed in evening hours), whereas frontal passages accounted for most of them during the cold season. A different daily pattern was found in Bradford et al. [24] for a set of 34 locations in the same area. The author attributes this fact to a particular low convective activity during the period considered (summer 2009), which points to the idea that seasonal patterns of ramp events may vary from year to year. Nevertheless, the fact that this work analysed ramp events at individual locations whereas the former was based on the aggregated regional wind power was not remarked as a potential explanation.

Another interesting case study is the pilot project in the Alberta Electric System Operator (AESO) area [11,13], a relatively flat region situated close to a large mountain range. In this case, orographic effects were deemed to be determinant in explaining the challenging weather regimes observed. In [11] the main phenomena related to ramp events were described: shallow cold air, ${ }^{2}$ cross-mountain flows and cold surge events. From a statistical point of view, it was found that ramp-up events were more common than ramp-down events, the former taking place mainly from May to July and the latter during the period August-January.

Kamath [26] provided a statistical analysis on ramp event patterns for the aggregated wind power in the Bonneville Power Administration (BPA) balancing area in 2008 (with a installed capacity of around $1 \mathrm{GW}$ at the time). This region, situated in Pacific Northwest (USA), is characterised by a noticeable wind

${ }^{2}$ Wind farms are in the interface between a low level mass of cold air (characterised by light winds) and a strong cross-mountain flow of warm air resource, which has led to a concentrated development of wind projects. It was found that both ramp-up and ramp-down events happened more often in the afternoon than in the morning, and also from March to August. In line with previous works, ramp-up events were more common than downward ramps. Barbour et al [21] reported some characteristics observed in three different wind projects located in this region, concluding that the size of the project has an impact on the number of ramps (in such a way that smaller projects with less spatial diversity showed a higher number of ramps), whereas differences in ramp intensities were mainly associated to the specific location of the wind farms.

Kamath [30] analysed the relation between daily averaged weather measurements and ramp events in two regions with important wind penetration levels: the Tehachapi Pass (that belongs to the area of the California Independent System Operator, CAISO) and the Columbia Basin (BPA area). Based on feature selection techniques, the author concluded that wind measurements (in particular, average wind speed, speed gusts and wind direction) were of main interest in detecting days with ramp occurrence in both regions. It was also noted that the average air temperature and the average relative humidity measured in specific weather stations were also relevant for the case of the Tehachapi region.

Walton et al. [46] analysed spatial consistency of ramp events in Iowa (U.S.) by relating ramp underlying meteorological causes and time lags between ramps observed at different locations (within $160 \mathrm{~km}$ ). Results suggested that ramp occurrence in the presence of a strong pressure gradient propagated faster (less than $2 \mathrm{~h}$ ) than those related to a frontal passage (between 3 and $6 \mathrm{~h}$ ). Probably, the main limitation of the work is that it deals with wind speed data. Hence, ramps are defined in terms of fast wind speed variations, while power ramps can also be motivated by issues concerning the wind-to-power conversion process (yaw misalignment, wind turbine shut-down or severe mutual interference between wind turbines). The author also discusses the extent to which wind a ramp observed at $10 \mathrm{~m}$ entails a wind ramp at $80 \mathrm{~m}$ (hub height), given that wind observations at $10 \mathrm{~m}$ height are usually more abundant.

A few works have recently studied the link between large scale atmospheric processes and ramp events [50,64]. In Gallego-Castillo [50], the focus is placed in the connection between meteorological data generated with a Global Circulation Model (GCM) and ramp events observed at the wind farm level. With this purpose, the author introduced a two-staged methodology based on Principal Component Analysis (PCA) and mutual information. Results concerning two wind farms in Spain suggested different degrees of connection between the global/synoptic scales and the wind power dynamics. In particular, regional wind regimes governed by the channelling effect of the Ebro valley (North-east of the Iberian peninsula) together with zonal pressure gradients (east-west) were found to be connected to ramp occurrence for one of the wind farms. Couto et al. [64] identified a number of synoptic weather regimes through a combination of PCA and clustering analysis in Portugal, and analysed their influence on ramp events experienced in the Portuguese power system. Strong ramp events were found to occur mostly in winter, ramp-up events being mainly caused by low pressure systems and frontal zones from the Atlantic Ocean, while ramp-down events were driven by the drop in wind speed due to the passage of low pressure centres in their motion towards the continent. Ramp events in summer were found to be of a lower intensity, and caused mainly by thermal low intensification in the Iberian peninsula. In addition, specific weather regime sequences were also identified as situations that may potentially lead to ramp events.

\section{Experiences on wind power ramp forecasting}

A ramp definition (addressed in Section 2) together with skills and tools oriented to identify underlying meteorological processes 
(Section 3) represents the basis of wind power ramp forecasting. Nonetheless, performing ramp forecasts is not straightforward. Indeed, owing to the novelty of the topic, there is a variety of approaches to the problem, revealing that there is no agreement on how ramp forecasts should be provided and evaluated. For instance, some works put emphasis on providing ramp alarms in terms of binary occurrence or probability distributions $[7,23,24]$ while others focus on forecasting ramp features, such as ramp rates $\left(\Delta P / \Delta t_{r}\right)[19]$. Moreover, the use of different ramp definitions (see Section 2) represents an additional difficulty when comparing results from different analyses. This section summarises the most relevant approaches to ramp forecasting reviewed, together with the main conclusions reported.

\subsection{Deterministic forecasting}

Cutler et al. [10] evaluated the performance of a conventional wind power forecasting methodology (i.e. not specifically oriented to ramp forecasting) during time periods where ramp events were observed. The case of a $65 \mathrm{MW}$ wind farm was considered. Wind power forecasts were obtained from the combination of BoM MesoLAPS and the Danish WPPT model. BoM MesoLAPS is an atmospheric Limited Area Model (LAM) with a horizontal resolution of $12.5 \mathrm{~km}$. WPPT performs wind power forecasts from recent local power observations, the time of the day and wind speed and direction forecasts at $10 \mathrm{~m}$ height provided by the LAM. The analysis was performed for prediction horizons comprised between 19 and $42 \mathrm{~h}$ ahead. It was concluded that the forecasting error observed during ramp events was similar to that committed by the reference model (the climatological mean). This result was mainly due to the low accuracy of the LAM model in predicting wind during these events. More specifically, timing errors (ramps predicted with a delay of a few hours) seemed to play an important role since they are severely penalised by the Root Mean Squared Error (RMSE) criterion. To the authors, this fact therefore questions the usefulness of the RMSE to evaluate the forecasting performance of wind power ramps.

Concerning the aforementioned Alberta forecasting pilot project (see Section 3), wind power forecasts up to 1-48 $\mathrm{h}$ ahead were provided by several forecasters. In this case, a wealth of NWP models were employed, so that a statistical stage was required to optimally generate the power forecast from the available meteorological outputs. Truewind [11] reported that the use of a global criterion to tune this step (minimisation of the RMSE) led to a systematic low accuracy of ramp rates prediction. Along these lines, Focken and Lange [13] remarked that models had to be tuned either to minimise a global criterion or to maximise the performance during ramp events, but both criteria could not be met at the same time. In addition, ramp-down events were found to be more difficult to predict that upward ramps [11].

The use of two NWP model outputs was considered in Greaves et al. [7] to predict the power output of both individual wind farms and portfolios. In this case, the analysis of the ramp forecasting accuracy was performed in base of a binary ramp classification. Under this approach, there are three possible outcomes for each observed/predicted ramp event:

- True Forecast (TF) (also referred to as Hits and True positive): a ramp event is observed and predicted within a specific time interval.

- False Forecast (FF) (also referred to as False alarm and False positive): a ramp event is predicted but not observed.

- Missed Ramp (MR) (also referred to as False negative): a ramp event is observed but not predicted.

Based on these definitions, the ramp forecasting accuracy can be assessed by defining the Forecast Accuracy (FA), the Ramp
Capture (RC) (also named hit percentage) and the Critical Success Index (CSI), as follows:

$$
\begin{aligned}
& \mathrm{FA}=\frac{\mathrm{TF}}{\mathrm{TF}+\mathrm{FF}}, \\
& \mathrm{RC}=\frac{\mathrm{TF}}{\mathrm{TF}+\mathrm{MR}} . \\
& \mathrm{CSI}=\frac{\mathrm{TF}}{\mathrm{TF}+\mathrm{FF}+\mathrm{MR}} .
\end{aligned}
$$

In the mentioned study [7], the combination of several NWP outputs for ramp forecasting was called into question as the related $\mathrm{RC}$ index was found to be lower than the one obtained through the use of a single NWP model. In addition, the authors noted that the use of a binary ramp definition poses certain problems for the evaluation of the ramp forecasting performance. For example, the MR index might be overestimated if it happens that a ramp is well predicted in timing but the predicted amplitude is slightly lower than the threshold of the employed ramp definition.

Bradford et al. [24] reported another wind power ramp forecasting experience based on a binary ramp definition. In this case, the use of a high resolution NWP model (the Weather Research and Forecasting model, WRF, at $3 \mathrm{~km}$ spatial resolution) along with a power curve model was employed to forecast wind power output at 34 locations over a one-month period. The RC index (see Eq. (5)) and Peirce's Skill Score (PSS) were employed. The PSS is defined as follows:

$\mathrm{PSS}=\frac{(\mathrm{TF} \cdot \mathrm{TN})-(\mathrm{FF} \cdot \mathrm{MR})}{(\mathrm{TF}+\mathrm{MR}) \cdot(\mathrm{FF}+\mathrm{TN})}$

where TN stands for True Negative (a ramp event is neither observed nor predicted). Both statistics showed a very low accuracy in predicting ramps, which was attributed to specific limitations of the methodology (such as the use of wind forecasts and observations at $2 \mathrm{~m}$ height) rather than to the WRF model performance.

Collier et al. [25] analysed the impact of considering upstream wind measurements to improve very short-term ramp forecasting (the considered prediction horizons ranged up to $6 \mathrm{~h}$ ). The basic idea was to refine wind power forecasts obtained through conventional models (NWP model combined with recent SCADA observations) by adding information gathered in upstream locations (in the order of $100 \mathrm{~km}$ ). It was found that the use of the forecast error observed at the upstream locations provided more information than using raw upstream measurements. The analysis showed that the ramp capture improvement was limited, although better forecasts of ramp features such as the ramp rate were observed. However, two limitations should be remarked: (i) only ramps related to a specific wind direction were considered and (ii) those ramps due to cut-out speed were excluded from the analysis.

Yang et al. [56] discussed the impact of the planetary boundary layer (PBL) parameterization on the ramp forecasting performance. Three different PBL parameterizations were considered. The authors concluded that one of them showed the best overall performance under stable conditions, while no single PBL parameterization clearly outperformed the others when all atmospheric conditions were considered.

Only a few works have focused on purely time series based models applied to ramp forecasting, i.e. with no NWP data as inputs. Zheng and Kusiak [19] presented a study on time series models for wind power ramp rate forecast. The ramp rate time series was obtained from the difference between two consecutive power measurements in a 10 -min basis (the first-difference of the wind power time series). A set of meaningful explanatory variables was identified from SCADA measurements. Several multi-variate time series models were built and compared for different 
prediction horizons between 10 and $60 \mathrm{~min}$. It was found that a support vector machine (SVM) algorithm outperformed the rest of the models, providing reasonable forecasts for horizons up to $40 \mathrm{~min}$. Unfortunately, the authors do not provide insights about the advantages of forecasting the first-difference of the time series instead of predicting the power time series directly.

Gallego-Castillo et al. [34] proposed a regime-switching model based on artificial neural networks (ANNs) in an effort to differentiate ramp and non-ramp regimes; to this end, the proposed model considered different ANN architectures and regression windows for each regime. The current regime was assessed at each time-step in base of the most recent observation of the wind power gradient. A noticeable improvement for the case of one hour-ahead forecast was attained, specially for the case of rampup events. However, the trial-and-error procedure involved in the ANN training was deemed to have a negative impact on the identification of the regime thresholds.

Ferreira et al. [40] employed a supervised learning algorithm to capture ramp events through a Hidden Markov Model (HMM) in a large scale wind farm located in US Midwest. Conversely to the approach addressed in [34], HMMs allow the modelling of ramp regimes as a non-observable process whose probabilities have been inferred from data. An interesting point of this work is that, in order to account for ramp seasonal patterns, the algorithm continuously updates the HMM with the most recent NWP outputs and SCADA measurements. This model was implemented for very short-term forecasting (30-90 min ahead), and demonstrated better performance than persistence.

A detailed analysis for very short-term wind power ramp forecasting was presented by Gallego-Castillo [50], where the author considered several type of time series based models (linear autoregressive, varying coefficient and ANN models) in order to discuss, among other factors, the role of the model complexity into the ramp forecasting performance. This study also analysed the impact of incorporating atmospheric information on the model performance. It was found that (i) atmospheric information improved ramp forecasting for all the case studies and models and (ii) the observed improvement was more sensitive to the identification of proper meteorological variables rather than to the statistical model choice.

\subsection{Probabilistic forecasting}

Some works have recently pointed out the potential contribution of probabilistic forecast to wind power ramp prediction [8,23,54]. Indeed, estimating probability distributions of ramp features such as amplitude, timing and duration would allow forecasters to better communicate complex situations rather than providing pointforecasts. This information permits end-users to be aware about different risk levels during decision-making processes.

Potter et al. [8] represents one of the first works describing the advantages of a probabilistic ramp forecasting approach. A discussion about proper evaluation methods for such forecasts is addressed, with special emphasis placed on the Reliability Diagram (RD). The notion of reliability is widely employed in probabilistic wind power forecasting [67]. In the case of ramp events, a $\mathrm{RD}$ aims at reflecting the agreement between the relative frequency of the observed and the predicted ramps. Another interesting contribution in [8] has to do with the value of ramp forecasting in terms of system operation costs. The author summarises the operation costs as follows:

Cost $=H+F+\frac{M}{r}$

where $H$ is the cost that is incurred to cover a forecast event, $F$ is the cost associated to purchasing ancillary services not needed, $M$ relates the costs of a non-predicted event and $r$ is the ratio between the cost of pre-purchasing ancillary services and the penalty incurred when a ramp event is not covered. From this conceptual expression, it is possible to argue that, for low values of the ratio $r$, the most cost-effective option is to include ramp forecasts into the operation process.

Special interest has been paid to the temporal uncertainty of ramp events. This is so because the phase error committed by NWP models entails ramps well predicted in amplitude but not in timing, which severely penalises the performance of power point-forecasts and binary ramp occurrence predictions. A first attempt to characterise the temporal uncertainty of ramp events was carried out by Greaves et al. [7]. The probability distribution of the delay (positive or negative) between observed ramps and predicted ramps was estimated for two different prediction horizons ( $3 \mathrm{~h}$ and $24 \mathrm{ho}$ ). This probability distribution, situated in the central part of a predicted ramp, was utilised to inform about the timing temporal uncertainty in a visual manner. An important limitation of this work is that the estimated probability distribution of the delay is non-time-dependent because it was estimated once for all the events. Consequently, the analysis on different uncertainty levels for different underlying ramp causes was not addressed.

Bossavy et al. [23] proposed a methodology based on ensemble forecasts to provide confidence intervals for ramp-timing estimation. Ensemble forecasting makes reference to a forecasting strategy based on the use of a wealth of future meteorological scenarios, referred to as members, which are obtained by running a NWP model with smal perturbations in the initial state and/or different parametrizations. The case of three wind farms located in France was considered, and the Ensemble Prediction System of the ECMWF was employed. Each ensemble member was used to estimate wind power forecasts from 1 to $80 \mathrm{~h}$ ahead. When a ramp event was predicted by a number of members, the related timing values were employed to infer a statistical distribution of the ramp timing, leading to better results than those obtained with a reference model. The performance evaluation was based on the Brier Score (BS), which measures the accuracy of the predicted probabilities for events with two categories (binary outputs). The BS is usually defined as

$\mathrm{BS}=\frac{1}{N} \sum_{i}^{N}\left(p_{i}-r_{i}\right)^{2}$,

where $p_{i}$ is the probability of ramp occurrence within a time interval, $r_{i}$ is the observed event index ( 0 for non-ramp and 1 for ramp occurrence) and $N$ is the number of provided probabilities. This procedure was further explored by Bossavy et al. [54], concluding that the use of ensembles provides a more reliable ramp capture than the one obtained with a unique wind power scenario.

Zack et al. [27] developed a ramp oriented wind power forecasting tool to generate very short-term probabilistic forecasts of the ramp rate. The forecasts consist of a set of graphics reflecting the probability to observe ramp rates larger than several pre-established thresholds for several horizons, from $15 \mathrm{~min}$ to $6 \mathrm{~h}$ ahead. Ramp rates were defined for three different time periods, namely 15,60 and $180 \mathrm{~min}$. Wind power point-forecasts were also provided together with $80 \%$ confidence bands. The probabilistic forecasts were evaluated with the Ranked Probability Score (RPS), which generalises the aforementioned BS for more than two categories [68].

Ferreira et al. [52] introduced a new approach to the problem of probabilistic ramp detection. The method employs a Monte Carlo sampling process to build a number of power generation scenarios. From these scenarios, the probabilities of observing a power gradient exceeding a certain threshold were computed for each time step. According to the authors, such form of the outputs enables TSOs to address (stochastic) unit commitment properly, since it is possible to evaluate the risk level for different situations in such a way that the adopted decisions depend ultimately on the 
Table 3

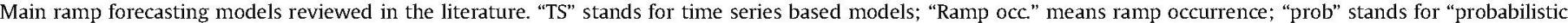
model".

\begin{tabular}{|c|c|c|c|c|}
\hline Author & Model type & Horizons & Outputs & Evaluation metrics \\
\hline Cutler [10] & $\mathrm{NWP}+\mathrm{TS}$ & $19-42 \mathrm{~h}$ & Power output & RMSE \\
\hline Truewind [11] & NWP & $1-48 \mathrm{~h}$ & Power output & MAE, RMSE \\
\hline Greaves [7] & NWP & $3-24 \mathrm{~h}$ & Ramp occ. & $\mathrm{FA}, \mathrm{RC}$ \\
\hline Zheng [19] & TS & $10-60 \mathrm{~min}$ & Ramp rate & MAE \\
\hline Bradford [24] & NWP & $0-24 \mathrm{~h}$ & Ramp occ. & RC, PSS \\
\hline Collier [25] & NWP & $0-6 h$ & Ramp occ. & $\mathrm{RC}$ \\
\hline Bossavy [23] & NWP & $1-48 \mathrm{~h}$ & Ramp occ (prob) & $\mathrm{RD}$ \\
\hline Zack [27] & NWP & $15 \min -6 \mathrm{~h}$ & Ramp occ (prob) & RPS \\
\hline Gallego-Castillo [34] & TS & $1-5 \mathrm{~h}$ & Power output & RMSE \\
\hline Ferreira [40] & TS & $30-90 \mathrm{~min}$ & Ramp occ. & PSS \\
\hline Bossavy [54] & Ensembles & $1-80 \mathrm{~h}$ & Ramp timing (prob) & BS \\
\hline Yang [56] & NWP & $12-36 \mathrm{~h}$ & Ramp occ & $\mathrm{FA}, \mathrm{RC}$ \\
\hline Gallego-Castillo [50] & TS & $1-6 h$ & Power output & Weighted RMSE \\
\hline Ferreira [52] & Monte Carlo & $1-24 \mathrm{~h}$ & Ramp occ. (prob) & $\mathrm{CSI}, \mathrm{ROC}$ \\
\hline Ellis [66] & NWP & $6 \mathrm{~h}$ & Ramp occ (prob) & $\mathrm{ROC}, \mathrm{RD}$ \\
\hline
\end{tabular}

risk assumed by the TSO. The receiver operating characteristic (also referred to as ROC curve) was employed as a means to evaluate the experimental results. The idea behind the ROC curve is to reflect the sensitivity of the model in discriminating true positives and false positives with respect to some parameter (e.g. the amplitude threshold).

More recently, Ellis et al. [66] analysed the performance of several models in predicting high variability events (ramp events but also fluctuation periods). As inputs, the considered models employed meteorological reanalysis data previously processed through PCA. A single wind farm with a rated power of $80 \mathrm{MW}$ located in Australia was employed as case study. In line with previous studies, the results of the analysis suggested that meteorological information over large geographical areas contributed to improve forecasts, though the performance was found to decrease with the severity of the ramp event.

Table 3 summarises the main ramp forecasting models reviewed in the literature together with their main characteristics.

\section{Conclusions and recommendations}

Wind power ramp forecasting is a relatively recent topic motivated by the need of improving the management of large and fast wind power output variations, specially in a context of power systems with high wind penetration. Since 2007, the number of related works has increased progressively. The present study provides a review covering up to August 2014, and organised into three main topics: (i) ramp definition, (ii) ramp underlying meteorological causes and (iii) experiences reported on wind power ramp forecasting. This review allowed us to identify the following weak points concerning ramp forecasting that shall be addressed in the future:

1. Ramp event definition: There exists a broad range of ramp definitions in the literature, most of them relying on the binary approach (ramp/non-ramp). The related thresholds were usually assessed ad hoc, suggesting a lack of agreement with end-users. In this regard, practices as that followed by Cutler et al. [28] should be followed. On the other hand, non-binary approaches recently proposed seem to achieve a more robust ramp characterisation. However, they are less intuitive and end-users might be initially reluctant to use them.

2. Explanatory variables: Ramp underlying causes have been studied and described in a wealth of works, with special focus placed on meteorological processes at different time/spatial scales. However, because of the complex nature of ramps, expertise gained from the reported experiences cannot be easily generalised to other case studies. Thus, from an operational point of view, advanced methodologies oriented to identify information (meteorological, but also from the wind farm state) relevant in explaining ramp occurrence should be further investigated. These methodologies shall provide explanatory variables, in the form of lowdimensional signals, to optimally feed ramp forecasting models.

3. Optimal outputs: Probably due to the novelty of the topic, what constitutes the optimal output of a ramp-oriented forecasting tool is still unclear. Ramp event alerts, probabilistic ramp event occurrence and ramp rate forecast represent some examples of the different ramp forecasting standpoints reviewed. In this regard, in order to prevent the development of ramp forecasting tools whose contribution is not clear [35], the role of ramp events into the various decision-making problems involved in wind power integration deserves further analyses.

4. Ramp forecast value: It is generally accepted that wind power forecasts benefit end-users differently [69]. In this regard, specific cost-functions describing the impact of ramp events on the different end-user activities are still required. A followup of the analysis introduced in Potter et al. [8] should be addressed, assessing specific cost values for specific case studies. This is the base to have forecasters design models well-suited for real-life problems.

\section{References}

[1] Peters R, O'Malley L. Storing renewable power. Technical report. The Pembina Institute; 2008. Available at $\langle$ http://pubs.pembina.org/reports/StoringRenewa blePower-jun17.pdf $>$ [August 20, 2014].

[2] Costa A, Crespo A, Navarro J, Lizcano G, Madsen $H$, Feitosa E. A review on the young history of the wind power short-term prediction. Renew Sustain Energy Rev 2008;12(6):1725-44. http://dx.doi.org/10.1016/j.rser.2007.01.015.

[3] Giebel G. The state of the art in short-term prediction of wind power-a literature overview (2nd ed.). Technical report. ANEMOS.plus/SafeWind projects; 2011.

[4] Jung J, Broadwater R. Current status and future advances for wind speed and power forecasting. Renew Sustain Energy Rev 2014;31:762-77. http://dx.doi. org/10.1016/j.rser.2013.12.054.

[5] Ela E, Kirby B. Ercot event on february 26, 2008: lessons learned. Technical report. NREL; 2008. Available at http://www.nrel.gov/docs/fy08osti/43373. pdf) [July 10, 2014].

[6] Wan Y. Analysis of wind power ramping behavior in ERCOT. Technical report. NREL; 2011. Available at 〈http://www.nrel.gov/docs/fy11osti/49218.pdf) [July $10,2014]$.

[7] Greaves B, Collins J, Parkes J, Tindal A. Temporal forecast uncertainty for ramp events. Wind Eng 2009;33(4):309-20. http://dx.doi.org/10.1260/0309524097 89685681.

[8] Potter C, Grimit E, Nijssen B. Potential benefits of a dedicated probabilistic rapid ramp event forecast tool. In: IEEE/PES power systems conference and exposition, March 2009, Seattle, Washington; 2009. p. 1-5. http://dx.doi.org 10.1109/PSCE.2009.4840109. 
[9] Zack J. Optimization of wind power production forecast performance during critical periods for grid management. Technical report; 2007. Available at 〈http://www.awstruepower.com/wp-content/media/2010/05/AWEA_Wind power_2007_Forecasting.pdf) [March 23, 2014]

[10] Cutler N, Kay M, Jacka K, Nielsen T. Detecting, categorizing and forecasting large ramps in wind farm power output using meteorological observations and WPPT. Wind Energy 2007;10(5):453-70. http://dx.doi.org/10.1002/ we. 235

[11] Truewind A. AWS Truewind's final report for the Alberta forecasting pilot project. Technical report; 2008. Available at (http://www.uwig.org/Alberta PP_Final_Report_AWST_Jun25.pdf) [June 2, 2014].

[12] Freedman J, Markus M, Penc R. Analysis of West Texas wind plant ramp-up and ramp-down events. Technical report; 2008. Available at change.puc.state.tx.us/WebApp/Interchange/Documents/33672_1014_580034. PDF> [July 10, 2014].

[13] Focken U, Lange M. Wind power forecasting pilot project in Alberta, Canada. Final report. Technical report; 2008. Available at $\langle$ http://www.uwig.org/Final report_emsys_lv.pdf $\rangle$ [July 9, 2014]

[14] Grimit E, Potter C. Prototype day-ahead forecast system for rapid wind ramp events. In: Windpower conference and exhibition, Houston, TX; 2008.

[15] Ela E, Kemper J. Wind plant ramping behavior. Technical report. NREL; 2009. Available at (http://www.nrel.gov/docs/fy10osti/46938.pdf) [July 11, 2014]

[16] Pinson P. Catalogue of complex to extreme situations. Technical report SafeWind project; 2009. Available at $\langle$ http://www.safewind.eu/images/Arti cles/Deliverables/swind_deliverable_dc-1.2_cataloguesextremeevents_v1.1. pdf) [June 17, 2013].

[17] Pease J. Critical short-term forccasting needs for large and unscheduled wind energy on the BPA system. In: Conference at the 3rd workshop on best practice in the use of short-term forecasting of wind power, Bremen; 2009.

[18] Cutler N. Characterising the uncertainty in potential large rapid changes in wind power generation [Ph.D. thesis]. School of Electrical Engineering and Telecommunications, University of New South Wales; 2009. Available at 〈http://unsworks.unsw.edu.au/fapi/datastream/unsworks:5018/SOURCE02〉 [September 10, 2014].

[19] Zheng H, Kusiak A. Prediction of wind farm power ramp rates: a data-mining approach. J Solar Energy Eng-Trans ASME 2009;131:3. http://dx.doi.org/ $10.1115 / 1.3142727$

[20] Cutler N, Outhred H, MacGill I, Kay M, Kepert J. Characterizing future large, rapid changes in aggregated wind power using Numerical Weather Prediction spatial fields. Wind Energy 2009;12(6):542-55. http://dx.doi.org/10.1002/ we.312.

[21] Barbour P, Casey S, Walker S. Evaluation of BPA vendors wind plant "wind ramp event" tracking system. Technical report; 2010. Available at $\langle$ http://web. engr.oregonstate.edu/ barboup/publications/Wind_Ramp_Report_OSU FR-PUB.pdf) [July 21, 2014]

[22] Ferreira C, Gama J, Matias L, Botterud A, Wang J. A survey on wind power ramp forecasting. Technical report. Argonne National Laboratory; 2010. Available at 〈http://www.dis.anl.gov/pubs/69166.pdf) [April 30, 2014]

[23] Bossavy A, Girard R, Kariniotakis G. Forecasting uncertainty related to ramps of wind power production. In: European wind energy conference, Warsaw; April 2010.

[24] Bradford K, Carpenter R, Shaw B. Forecasting southern plains wind ramp events using the WRF model at 3-Km. In: 9th American meteorological society student conference, Atlanta, Georgia; January 2010. Available at 〈https://ams. confex.com/ams/pdfpapers/166661.pdf) [April 13, 2014].

[25] Collier C, Parkes J, Collins J, Landberg L. Improved ramp event forecasting using upstream wind measurements. In: European wind energy conference, Warsaw; April 2010.

[26] Kamath C. Understanding wind ramp events through analysis of historical data. In: IEEE PES transmission and distribution conference and exposition: smart solutions for a changing world; New Orleans, LA. IEEE Power \& Energy Society; April 2010. ISBN 978-1-4244-6547-7. http://www.springer.com/us/ book/9788132209867\#aboutBook.

[27] Zack J, Aymamí J, Vidal-Pérez J, Tortosa-Andreu A. An innovative short-term large wind ramp forecasting system. Geophysical research abstracts, vol. 12, EGU General Assembly; 2010.

[28] Cutler N, Outhred H, MacGill I. Final report on UNSW Project for AEMO to develop a prototype wind power forecasting tool for potential large rapid changes in wind power. Technical report. Centre for Energy and Environmental Markets - University of New South Wales; 2011

[29] Girard R, Bossavy A, Kariniotakis G. Forecasting ramps of wind power production at different time scales. In: European wind energy conference, Brussels; March 2011.

[30] Kamath C. Associating weather conditions with ramp events in wind power generation. In: IEEE/PES power systems conference and exposition, Phoenix Arizona; March 2011. p. 1-8. http://dx.doi.org/10.1109/PSCE.2011.5772527.

[31] Zareipour $H$, Huang D, Rosehart W. Wind power ramp events classification and forecasting: a data mining approach. In: 2011 IEEE Power and energy society general meeting; 2011. p. 1-3. http://dx.doi.org/10.1109/PES.2011.6039625.

[32] Musilek P, Li Y. Forecasting of wind ramp events-analysis of cold front detection. In: 31th international symposium on forecasting, Prague, Czech Republic; June 2011.

[33] Bossavy A, Girard R, Kariniotakis G. A probabilistic approach to forecast ramps of wind power production using ensembles. In: 11th EMS annual meeting \& 10th European conference on applications of meteorology (ECAM), Berlin, Germany; September 2011
[34] Gallego-Castillo C, Costa A, Cuerva-Tejero A. Improving short-term forecasting during ramp events by means of Regime-Switching Artificial Neural Networks. Adv Sci Res 2011;6:55-8. http://dx.doi.org/10.5194/asr-6-55-2011.

[35] Pinson P, Otterson S. Are ramp forecasts useful? In: European wind energy conference, Copenhagen; April 2012

[36] Gallego-Castillo C, Cuerva-Tejero A, Costa A. Detecting and characterising ramp events in wind power time series. J Phys: Conf Ser 2014;555:012040. http://dx.doi.org/10.1088/1742-6596/555/1/012040 [The Science of Making Torque from Wind 2012].

[37] Lee D, Kim J, Baldick R. Ramp rates control of wind power output using a storage system and Gaussian processes. In: 31 USAEE/IAEE North America conference, Texas; November 2012. ISBN 978-1-4244-6547-7.

[38] Li Y, Musilek P, Lozowski EP. Forecasting wind ramps from pressure trough progression. In: 12th EMS annual meeting \& 9th european conference on applied climatology (ECAC), vol. 9, Lódź, Poland; September 2012.

39] Oi Y, Liu Y. Finite control on wind power ramping event. In: IPEC, 2012 conference on power energy; 2012. p. 655-8. http://dx.doi.org/10.1109/ASSCC. 2012.6523346.

[40] Ferreira CA, Gama J, Santos Costa V, Miranda V, Botterud A. Predicting ramp events with a stream-based HMM framework. In: Discovery science Lecture notes in computer science, vol. 7569. Berlin Heidelberg: Springer; 2012. p. 224-38. ISBN 978-3-642-33491-7. http://dx.doi.org/10.1007/978-3-642-33492-4_19.

41] Bossavy A. Characterization and probabilistic forecasting of wind power ramps [Ph.D. thesis]. École Nationale Supérieure des Mines de Paris; 2012. Available at (http://www.nrel.gov/docs/fy08osti/43373.pdf) [June 3, 2014].

42] Fernández A, Alaíz CM, González A, Díaz J, Dorronsoro JR. Diffusion methods for wind power ramp detection. In: Rojas I, Joya G Gabestany I cditors. Advances in computational intelligence. Lecture notes in computer science. vol. 7902. UMA and UGR and UPC and ULL; Heidelberg, Germany: SpringerVerlag GmbH; 2013. p. 106-13. ISBN 978-3-642-38678-7.

[43] Florita A, Hodge BM, Orwig K. ldentifying wind and solar ramping events. In: 2013 IEEE green technologies conference; 2013. p. 147-52. http://dx.doi.org 10.1109/GreenTech.2013.30.

[44] Bossavy A, Girard R, Kariniotakis G. A novel methodology for comparison of different wind power ramp characterization approaches. In: European wind energy conference, Vienna; February 2013.

[45] Suzuki A, Shaw P, Collier C, Parkes J, Landberg L. Use of offsite data to improve short term ramp forecasting. In: European wind energy conference, Vienna February 2013.

[46] Walton R, Gallus Jr W, Takle ES. Wind ramp events at turbine height-spatial consistency and causes at two lowa wind farms. In: Fourth conference on weather, climate, and the new energy economy, Austin, TX; January 2013.

[47] Reddy C, Balaraman K, Patil A, Vasudevan K. Wind power ramp forecasting for stochastic unit commitment in smart grid environment. In: 2013 IEFE innovative smart grid technologies-Asia (ISGT Asia); 2013. p. 1-6. http://dx doi.org/10.1109/ISGT-Asia.2013.6698762.

[48] Ma H, Liu Y. Real-time recognition of wind power ramp events. In: 2nd IET renewable power generation conference (RPG 2013); 2013. p. 1-4. http://dx. doi.org/10.1049/cp.2013.1813.

[49] Mullen J, Osman M. Wind power ramping in the Bonneville Power Administration area. In: 1st IEEE conference on technologies for sustainability (SusTech); 2013. p. 196-202. http://dx.doi.org/10.1109/SusTech.2013.6617320.

[50] Gallego-Castillo C. Statistical models for short-term wind power ramp forecasting [Ph.D. thesis]. Escuela Técnica Superior de Ingenieros Aeronáuticos, Universidad Politécnica de Madrid; 2013. Available at 〈http://oa.upm.es/ 21912> [September, 2013].

[51] Das AK, Mazumdar BM. A statistical model for wind power on the basis of ramp analysis. Int. J. Green Energy 2013; http://dx.doi.org/10.1080/15435075. 2013.849257. Published online.

[52] Ferreira C, Gama J, Miranda V, Botterud A. Probabilistic ramp detection and forecasting for wind power prediction. In: Reliability and risk evaluation of wind integrated power systems. Springer; 2013. p. 29-44.

[53] Gallego-Castillo C, Costa A, Cuerva-Tejero A, Landberg L, Greaves B, Collins J. A wavelet-based approach for large wind power ramp characterisation. Wind Energy 2013;16(2):257-78. http://dx.doi.org/10.1002/we.550.

[54] Bossavy A, Girard R, Kariniotakis G. Forecasting ramps of wind power production with numerical weather prediction ensembles. Wind Energy 2013;16(1):51-63. http://dx.doi.org/10.1002/we.526.

[55] Sevlian R, Rajagopal R. Detection and statistics of wind power ramps. IEEE Trans Power Syst 2013;28(4):3610-20. http://dx.doi.org/10.1109/TPWRS.2013. 2266378.

[56] Yang Q Berg Lamy K, Pekour M, Fast JD, Newsom RK, Stoelinga M, et al. Evaluation of WRF-Predicted Near-Hub-Height Winds and Ramp Events over a Pacific Northwest Site with Complex Terrain. I Appl Meteorol Climatol 2013;52 (8): 1753-63.

[57] Heckenbergerova J, Musilek P, Marek I. Analysis of wind speed and power time series preceding wind ramp events. In: Proceedings of the 15 th international scientific conference on electric power engineering (EPE); 2014. p. 279-83.

[58] Revheim PP, Beyer HG. Offshore ramp forecasting using offsite data. In: EERA DeepWind 2014 deep sea offshore wind R\&D conference, Trondheim, Norway: January 2014

[59] Gallego-Castillo C, Garcia-Bustamante E, Cuerva A, Navarro J. On the relation between wind power ramps and the global/synoptic scales. In: European wind energy conference, Barcelona, Spain; March 2014.

[60] Zhang J, Florita A, Hodge BM, Freedman J. Ramp forecasting performance from improved short-term wind power forecasting. In: ASME International Design 
Engineering Technical Conf. \& Computers and Information in Engineering Conf. IDETC/CIE, Buffalo, New York, USA, Aug. 2014

[61] Gan D, Ke D. Wind power ramp forecasting based on least-square support vector machine. Appl Mech Mater 2014;535:162-6. http://dx.doi.org/10.4028/ www.scientific.net/AMM.535.162.

[62] Martínez-Arellano G, Nolle L, Cant R, Lotfi A, Windmill C. Characterisation of large changes in wind power for the day-ahead market using a fuzzy logic approach. Künstliche Intell 2014; 28(4):239-53; http://dx.doi.org/10.1007 s13218-014-0322-3.

[63] Bossavy A, Girard R, Kariniotakis G. An edge model for the evaluation of wind power ramps characterization approaches. Wind Energy 2015; 18(7):1169-84; http://dx.doi.org/10.1002/we.1753.

[64] Couto A, Costa P, Rodrigues L, Lopes V, Estanqueiro A. Impact of Weather Regimes on the Wind Power Ramp Forecast in Portugal. IEEE Trans Sustain Energy 2014;99:1-9. http://dx.doi.org/10.1109/TSTE.2014.2334062.
[65] Ganger D, Zhang J, Vittal V. Statistical characterization of wind power ramps via extreme value analysis. IEEE Trans Power Syst 2014;99:1-2. http://dx.doi. org/10.1109/TPWRS.2014.2315491.

[66] Ellis N, Davy R, Troccoli A. Predicting wind power variability events using different statistical methods driven by regional atmospheric model output. Wind Energy 2015; 18(9):1611-28; http://dx.doi.org/10.1002/we.1779.

[67] Pinson P, Nielsen HA, Moller JK, Madsen H, Kariniotakis GN. Non-parametric probabilistic forecasts of wind power: required properties and evaluation. Wind Energy 2007;10(6):497-516. http://dx.doi.org/10.1002/we.230.

[68] Weigel AP. The discrete brier and ranked probability skill scores. Mon Weather Rev 2007;135:118-24. http://dx.doi.org/10.1175/MWR3280.1.

[69] Bessa RJ, Miranda V, Botterud A, Wang J. 'Good' or 'bad' wind power forecasts: a relative concept. Wind Energy 2011;14(5):625-36. http://dx.doi.org/10.1002/ we. 444 . 